Published every April, August and December

JURNAL RISET AKUNTANSI \& KEUANGAN

ISSN:2541-061X (Online). ISSN:2338-1507(Print). http://ejournal.upi.edu/index.php/JRAK

\title{
Kajian Pertumbuhan Minat dan Realisasi Investasi Penanaman Modal Asing (PMA) dan Penanaman Modal Dalam Negeri (PMDN) Provinsi Jawa Barat (Lokasi dan Sektor Usaha)
}

\author{
Dony Waluya Firdaus ${ }^{1}$, Dimas Widyasastrena ${ }^{2}$ \\ Program Studi Komputerisasi Akuntansi, FTIK, UNIKOM, Bandung, Indonesia
}

\begin{abstract}
Investment interest of PMA and PMDN of West Java Province based on location and sector of January - December 2015 at 27 (twenty-seven) regencies/cities reaching a total investment of Rp. 186,491,741,150,000 and total employment of 161,561 people, as well as total projects of 1,540 projects. With the growth of Foreign Investment (PMA) based on the Location of Regency / City and Business Sector of West Java Province reached Rp.135,324,226,250,000 and Domestic Investment Interest (PMDN) of Regency / City and Business Sector of West Java Province reached Rp.51,167,514,900,000. The realization of foreign direct investment (FDI 2015) based on the Location of Regency / City and Business Sector of West Java Province reached Rp.71,733,928,750,000 although in the beginning - the beginning of the year experienced a slowdown, meanwhile. Realization of Domestic Investment (PMDN) based on Location of Regency / City and Business Sector of West Java Province reaches Rp.49,783,024,065,583.
\end{abstract}

Keywords: Interest, Realization; Foreign Investment; Domestic Investment.

Abstrak. Minat Investasi PMA dan PMDN Provinsi Jawa Barat berdasarkan lokasi dan sektor Januari Desember 2015 di 27 (dua puluh tujuh) Kabupaten/Kota mencapai total investasi sebesar Rp. $186,491,741,150,000$ dan total penyerapan tenaga kerja sebanyak 161,561 orang, serta total proyek sebanyak 1,540 proyek. Dengan pertumbuhan Minat Penanaman Modal Asing (PMA) berdasarkan Lokasi Kabupaten/Kota dan Sektor Usaha Provinsi Jawa Barat mencapai sebesar Rp.135,324,226,250,000 dan pertumbuhan Minat Penanaman Modal Dalam Negeri (PMDN) Kabupaten/Kota dan Sektor Usaha Provinsi Jawa Barat mencapai sebesar Rp.51,167,514,900,000. Realisasi Penanaman Modal Asing (PMA) 2015 berdasarkan Lokasi Kabupaten/Kota dan Sektor Usaha Provinsi Jawa Barat mencapai Rp.71,733,928,750,000 meskipun di awal awal tahun mengalami perlambatan, sedangkan. Realisasi Penanaman Modal Dalam Negeri (PMDN) berdasarkan Lokasi Kabupaten/Kota dan Sektor Usaha Provinsi Jawa Barat mencapai mencapai Rp.49,783,024,065,583.

Kata Kunci: Minat, Realisasi, Penanaman Modal Asing (PMA), Penanaman Modal Dalam Negeri (PMDN).

Corresponding author. Email: 1'dony.firdaus@gmail.com, 22dimas_widyasastrena@hotmail.com

How to cite this article. Dony Waluya Firdaus, D. W. (2016). Kajian Pertumbuhan Minat Dan Realisasi Investasi Penanaman Modal Asing (PMA) Dan Penanaman Modal Dalam Negeri (PMDN) Provinsi Jawa Barat (Lokasi Dan Sektor Usaha). Jurnal Riset Akuntansi Dan Keuangan Program Studi Akuntansi Fakultas Pendidikan Ekonomi Dan Bisnis Universitas Pendidikan Indonesia, 4(1), 895-910. Retrieved from http://ejournal.upi.edu/index.php/JRAK/article/view/7714

History of article. Received: January 2016, Revision: Maret 2016, Published: April 2016

Online ISSN: 2541-061X. Print ISSN: 2338-1507. DOI :10.17509/jrak.v4i1.7714

Copyright@2016. Jurnal Riset Akuntansi dan Keuangan Program Studi Akuntansi FPEB UPI 


\section{PENDAHULUAN}

Para pemimpin ASEAN (Asosiasi Negara-Negara Asia Tenggara) melakukan langkah penting dalam integritas ekonomi dengan terwujudnya ASEAN Economic Community (AEC) atau Masyarakat Ekonomi ASEAN (MEA) pada tahun 2015 dengan langkah ASEAN sebagai pasar tunggal dan basis produksi.

Bappeda Jawa Barat dalam rencana kerja pemerintah daerah (RKPD) tahun 2016, menunjukkan pertumbuhan ekonomi Jawa Barat pada Tahun 2014 sebesar 5,07\%, melambat dibanding Tahun 2013 yang tumbuh sebesar $6,06 \%$. Perlambatan pertumbuhan PDRB tersebut terutama didorong oleh melemahnya konsumsi rumah tangga meskipun investasi dan konsumsi pemerintah meningkat. Tetapi secara akumulasi, Jawa Barat memiliki intensitas aktivitas perekonomian Jawa Barat yang cukup tinggi. Dengan jumlah penduduk terbanyak di Indonesia dan masih menjadi tujuan utama investasi PMA dan PMDN, kemampuan ekonomi Jawa Barat tumbuh di atas nasional. Pencapaian kinerja perekonomian Jawa Barat sendiri, tidak lepas dari upaya menjaga stabilitas perekonomian daerah. Fakta inilah yang membentuk daya saing Jabar berada pada urutan ke-4 di Indonesia.

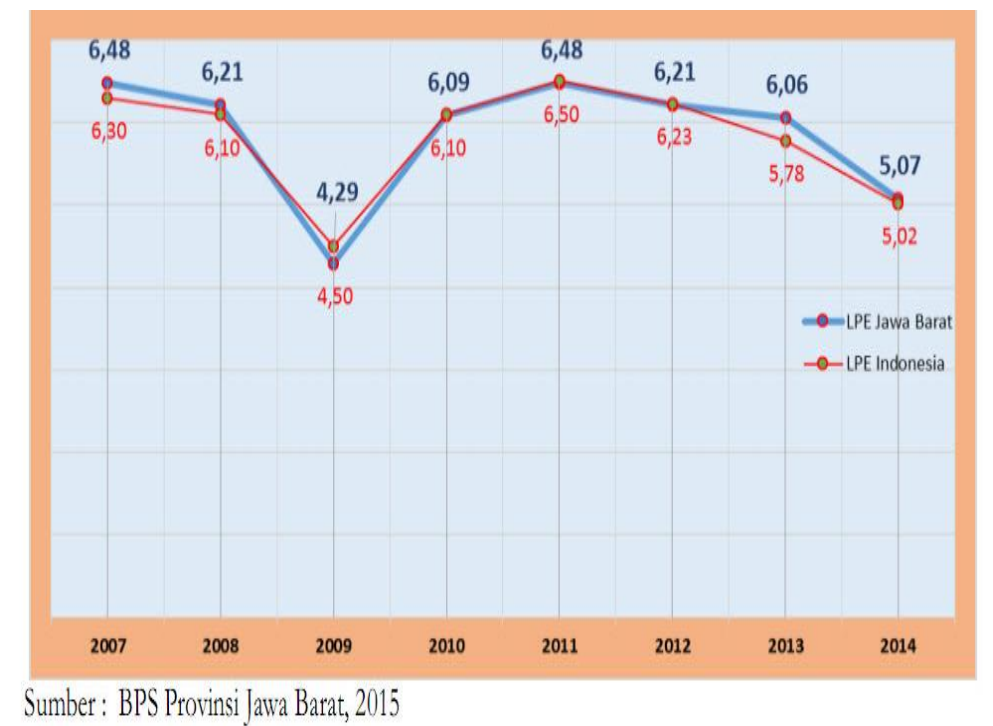

\section{Gambar 1. Laju Pertumbuhan Ekonomi (LPE) Jawa Barat 2007 - 2014}

Pertumbuhan terjadi pada seluruh lapangan usaha. Informasi dan Komunikasi merupakan lapangan usaha yang mengalami pertumbuhan tertinggi sebesar 17,47 persen, diikuti oleh Jasa Kesehatan dan Kegiatan Sosial sebesar 15,78 persen dan Jasa Pendidikan sebesar 14,43 persen. Sedangkan struktur perekonomian Jawa Barat menurut lapangan usaha Tahun 2014 didominasi oleh tiga lapangan usaha utama, yaitu Industri Pengolahan (43,57\%); Perdagangan BesarEceran dan reparasi Mobil-Sepeda Motor (15,24 persen) dan Pertanian, Kehutanan dan Perikanan ( 8,72 persen).
Rumusan Masalah dalam inti kajian penelitian ini adalah mengenai Minat dan Realisasi Investasi Penanaman Modal Asing

(PMA) dan Penanaman Modal Dalam Negeri (PMDN). Pokok masalah yang diungkap dalam penelitian ini adalah seberapa besar perkembangan Minat dan Realisasi Investasi Penanaman Modal Asing (PMA) dan Penanaman Modal Dalam Negeri (PMDN). Secara lebih rinci lingkup masalah penelitian ini yaitu seberapa besar pertumbuhan Penanaman Modal Asing (PMA) Provinsi Jawa Barat dan seberapa besar pertumbuhan Penanaman Modal Dalam Negeri (PMDN) Provinsi Jawa Barat. 


\section{KAJIAN LITERATUR}

Penelitian sebelumnya Lesty (2010) mengutip dari Badan Koordinasi Penanaman Modal dalam Ferdiyan (2006) investasi adalah kegiatan penanaman modal pada berbagai kegiatan ekonomi (produksi) dengan harapan untuk memperoleh keuntungan (benefit) pada masa-masa yang akan datang. Pada dasarnya investasi dibedakan menjadi investasi finansial dan investasi non finansial. Investasi finansial adalah bentuk pemilikan instrumen finansial seperti uang tunai, tabungan, deposito, modal dan penyertaan, surat berharga, obligasi dan sejenisnya. Investasi non finansial direalisasikan dalam bentuk investasi fisik (investasi riil) yang berwujud kapital atau barang modal, termasuk pula di dalamnya inventori (persediaan). Namun demikian, investasi finansial dapat juga direalisasikan menjadi investasi fisik. Berdasarkan konsep pendapatan nasional yang mengacu pada A System of National Account (UN, 1968) dalam BPS (2003), pengertian investasi adalah selisih antara stok kapital pada tahun (t) dikurangi dengan stok kapital pada tahun (t-1), atau setiap ada penambahan atau penimbunan modal.

Menurut Mankiw (2004), investasi terdiri dari barang-barang yang dibeli untuk penggunaan masa depan. Investasi dibagi menjadi tiga sub kelompok, yaitu investasi tetap bisnis, investasi tetap rumah tangga, dan investasi persediaan. Investasi tetap bisnis adalah pembelian pabrik dan peralatan oleh perusahaan; investasi tetap rumah tangga adalah pembelian rumah baru oleh rumah tangga dan tuan tanah; sedangkan investasi persediaan adalah peningkatan dalam persediaan barang perusahaan, barang dalam proses, dan barang jadi.

\section{Penanaman Modal Asing dan Penanaman Modal Dalam Negeri}

Sebagaimana dimuat dalam Peraturan Kepala Badan Koordinasi Penanaman Modal Republik Indonesia No 15 Tahun 2015 Tentang Pedoman Dan Tata Cara Perizinan Dan Nonperizinan Penanaman Modal, beberapa pengertian yang perlu dipahami antara lain (1) Penanaman Modal adalah segala bentuk kegiatan menanam modal, baik oleh Penanam Modal Dalam Negeri maupun Penanam Modal Asing, untuk melakukan usaha di wilayah negara Republik Indonesia. (2) Penanam Modal adalah perorangan atau badan usaha yang melakukan Penanaman Modal yang dapat berupa Penanam Modal Dalam Negeri dan Penanam Modal Asing. (3) Penanaman Modal Dalam Negeri, yang selanjutnya disingkat PMDN, adalah kegiatan menanam modal untuk melakukan usaha di wilayah negara Republik Indonesia yang dilakukan oleh Penanam Modal Dalam Negeri dengan menggunakan modal Dalam Negeri. (4) Penanaman Modal Asing, yang selanjutnya disingkat PMA, adalah kegiatan menanam modal untuk melakukan usaha di wilayah negara Republik Indonesia yang dilakukan oleh Penanam Modal Asing, baik yang menggunakan modal asing sepenuhnya maupun yang berpatungan dengan Penanam Modal Dalam Negeri.

Investasi asing atau biasa disebut Penanaman Modal Asing (PMA) adalah salah satu upaya untuk meningkatkan jumlah modal untuk pembangunan ekonomi yang bersumber dari luar negeri.

\section{Badan Penanaman Modal dan Perijinan Terpadu}

Pelayanan Terpadu Satu Pintu diatur dalam Peraturan Menteri Dalam Negeri No 24 Tahun 2006 tentang Pedoman Penyelenggaraan Pelayanan Terpadu Satu Pintu. Dalam peraturan ini, pelayanan atas permohonan perizinan dan non perizinan dilakukan oleh Perangkat Daerah Penyelenggara Pelayanan Terpadu Satu Pintu (PPTSP) yaitu perangkat pemerintah daerah yang memiliki tugas pokok dan fungsi mengelola sernua bentuk pelayanan perizinan dan non perizinan di daerah dengan sistem satu pintu.

Peraturan Presiden Republik Indonesia No. 97 Tahun 2014, Pelayanan Terpadu Satu Pintu, yang selanjutnya disingkat PTSP adalah pelayanan secara terintegrasi dalam satu kesatuan proses dimulai dari tahap permohonan sampai dengan tahap 
penyelesaian produk pelayanan melalui satu pintu.

\section{METODOLOGI PENELITIAN}

Metode yang digunakan dalam penelitian ini adalah kualitatif, sebagaimana yang diungkapkan J.R, Raco (2013) bahwa kualitataif sebagai pendekatan atau penulusuran untuk mengeksplorasi dan memahami suatu gejala sentral. Ciri khas dari metode kualitatif adalah induktif, dimana induktif biasanya mulai dengan mengobservasi sasaran penelitian secara rinci menuju generealisasi dan ide - ide yang abstrak. Dengan metode kualitatif, bahwa datanya selalu diperoleh dari tangan pertama dan berupa pengalaman langsung dari partisipan. Penelitian kualitatif yang digunakan adalah kualitatif deskriptif yang bertujuan untuk mengungkapkan suatu masalah atau keadaan tertentu sebagaimana adanya sehingga dapat memberikan gambaran secara tetap tentang keadaan yang sebenarnya dari objek yang diselidiki dalam rangka memecahkan masalah tertentu yang spesifik. (Kimbal. 2015).

Data yang diperlukan dalam penelitian ini adalah data primer dan sekunder. Data primer merupakan data yang dapat diperoleh lansung dari lapangan atau tempat penelitian. Data primer yang dimaksud berkaitan dengan pengukuran, observasi lapang, wawancara dan penyebaran kuesioner. Peneliti menggunakan data ini untuk mendapatkan informasi Minat dan Realisasi Investasi Penanaman Modal Asing (PMA) dan Penanaman Modal Dalam Negeri (PMDN) Provinsi Jawa Barat tahun 2015.

Data primer yang didapatkan/dikumpulkan langsung dari sumbernya. Data primer tersebut meliputi berbagai informasi dari Badan Penanaman Modal dan Perizinan Terpadu (BPMPT) Provinsi Jawa Barat, Badan Pusat Statistik
(BPS) Jawa Barat dan Badan Koordinasi Penanaman Modal (BKPM). Data primer yang akan dilakukan adalah perkembangan minat dan realisasi investasi PMA dan PMDN Provinsi Jawa Barat. Data sekunder merupakan data-data yang didapat dari kajian penelitian, tinjauan pustaka, koran, sampai dokumen-dokumen resmi dari berbagai instansi pemerintah. Data sekunder ini untuk memperkuat penemuan dan melengkapi informasi yang telah dikumpulkan melalui wawancara.

\section{HASIL DAN PEMBAHASAN}

\section{Minat Investasi PMA dan PMDN Berdasarkan Lokasi dan Sektor Usaha Januari - Desember 2015 \\ Minat Investasi PMA dan PMDN} Provinsi Jawa Barat berdasarkan lokasi dan sektor Januari - Desember 2015 di 27 (dua puluh tujuh) Kabupaten/Kota mencapai total investasi sebesar Rp. 186,491,741,150,000 dan total penyerapan tenaga kerja sebanyak 161,561 orang, serta total proyek sebanyak 1,540 proyek.

Peringkat 5 besar Kabupaten/Kota, yang paling diminati oleh para investor PMA/PMDN Januari - Desember 2015 dalam melaksanakan kegiatan usahanya, peringkat pertama adalah Kabupaten Subang dengan nilai investasi PMA dan PMDN mencapai Rp.65,071,655,600,000 dengan rasio investasi $34.89 \%$, rasio proyek $1.17 \%$ atau sebanyak 18 proyek, dan rencana menyerap tenaga kerja sebanyak 4.244 atau 2.63\%. Sedangkan peringkat kedua adalah Kabupaten Karawanag dengan nilai investasi PMA dan PMDN mencapai Rp.38,976,398,250,000 dengan rasio investasi sebesar $20.90 \%$ atau sebanyak 256 proyek lebih besar dari pada Kabupaten Subang, untuk 3 Kota/Kabupaten lainnya lebih jelas terlihat pada gambar 4.1. 


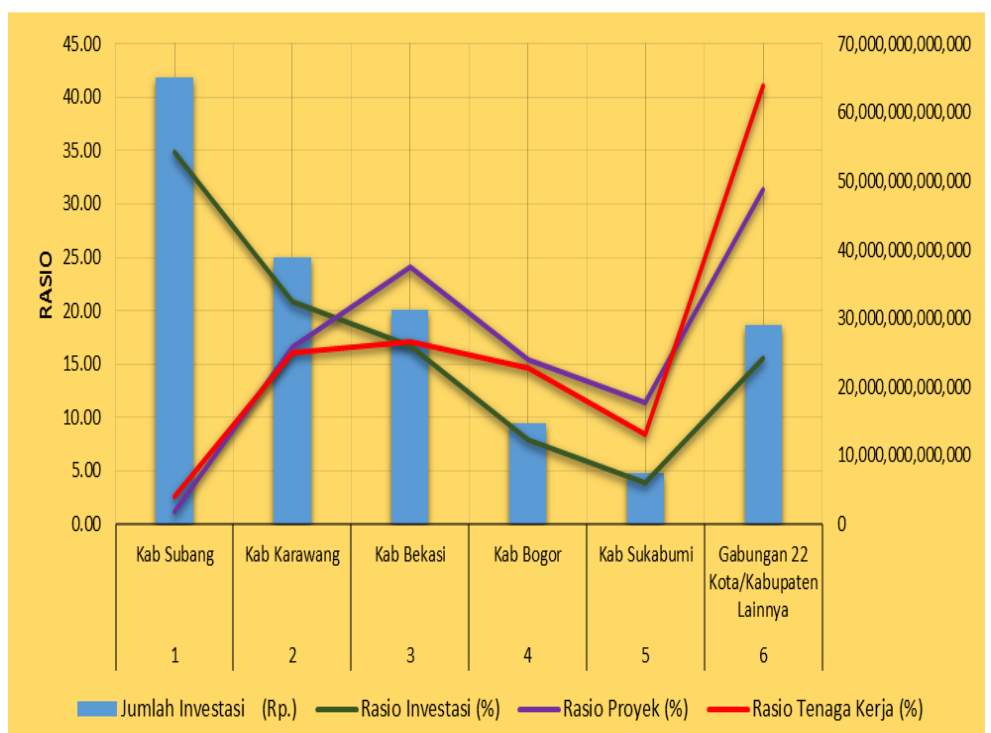

Sumber : Bidang Pengendalian BPMPT Provinsi Jawa Barat, Data Diolah

\section{Gambar 2. Lima Besar Minat Investasi PMA dan PMDN Jawa Barat Januari - Desember 2015 di Jawa Barat Berdasarkan Lokasi}

Investor tertarik melakukan investasi PMA dan PMDN Januari - Desember 2015 pada sektor usaha listrik, gas dan air dengan jumlah investasi

sebesar Rp.67,832,639,900,000 yang menduduki peringkat pertama dengan rasio investasi sebesar $36.37 \%$, sedangkan peringkat kedua yang diminati oleh investor adalah sektor usaha perumahan, kawasan industri dan perkantoran dengan nilai investasi sebesar Rp.25,859,511,100,000 dengan rasio investasi sebesar $13.87 \%$, untuk peringkat ketiga yang diminati investor adalah sektor usaha Industri kendaraan bermotor \& alat transportasi lain dengan nilai investasi sebesar Rp.25,169,642,950,000 dengan rasio investasi sebesar $13.50 \%$. Sektor usaha lainnya pada gambar dibawah ini.

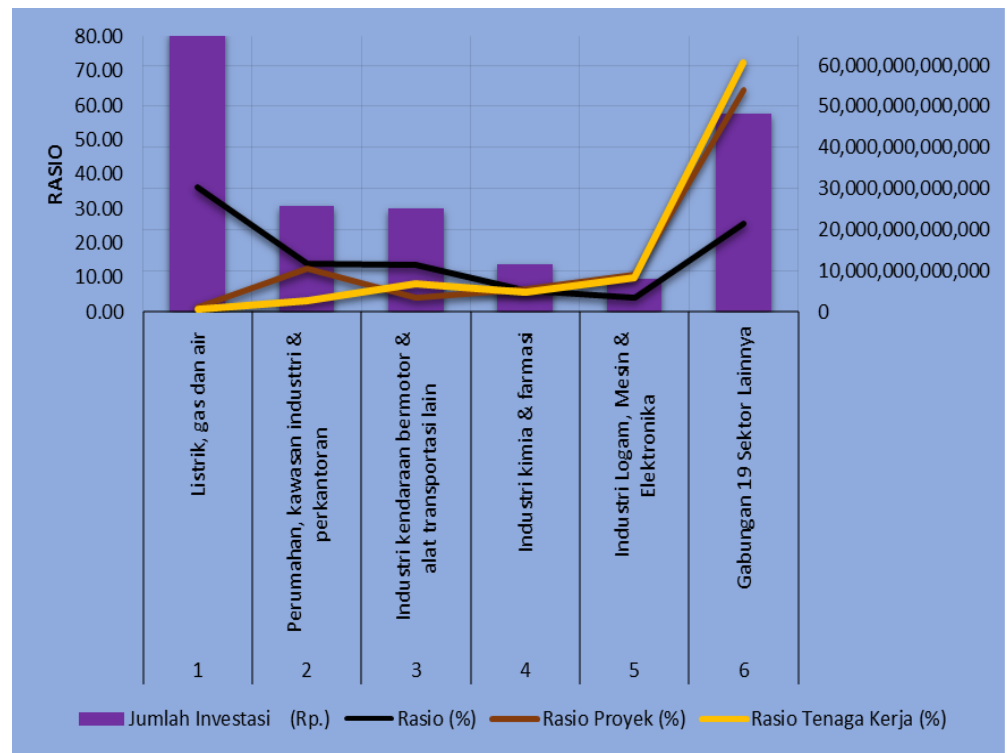

Sumber : Bidang Pengendalian BPMPT Provinsi Jawa Barat, Data Diolah

Gambar 3. Lima Besar Minat Investasi PMA dan PMDN Januari - Desember 2015 di Jawa Barat Berdasarkan Sektor Usaha 
Rencana investasi PMA yang diminati oleh investor berdasarkan lokasi di Jawa Barat Januari - Desember 2015 adalah mencapai sebesar Rp.135,324,226,250,000 dengan rencana tenaga kerja sebesar 83.479 orang, sedangkan rencana proyek PMA sebanyak 611 proyek, seperti dalam tabel 1 dibawah ini.

Tabel 1. Total Minat Investasi PMA Jawa Barat Januari - Desember 2015, Berdasarkan Lokasi.

\begin{tabular}{|c|c|c|c|c|c|}
\hline 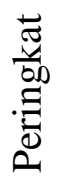 & KAB./KOTA & $\begin{array}{l}\text { Jumlah Investasi } \\
\text { (Rp.) }\end{array}$ & 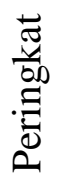 & KAB./KOTA & $\begin{array}{l}\text { Jumlah Investasi } \\
\text { (Rp.) }\end{array}$ \\
\hline 1 & Kab Subang & $64,891,962,500,000$ & 15 & Kota bandung & $608,210,000,000$ \\
\hline 2 & Kab Karawang & $24,331,316,250,000$ & 16 & Kota Cirebon & $581,660,000,000$ \\
\hline 3 & Kab Bekasi & $23,749,508,750,000$ & 17 & Kab Sumedang & $571,312,500,000$ \\
\hline 4 & Kab Bogor & $4,255,572,500,000$ & 18 & Kab Garut & $263,541,250,000$ \\
\hline 5 & Kab Bandung Barat & $2,972,327,500,000$ & 19 & Kab Cirebon & $230,300,000,000$ \\
\hline 6 & Kab Purwakarta & $2,668,585,000,000$ & 20 & Kota Cimahi & $94,223,750,000$ \\
\hline 7 & Kab Bandung & $2,535,687,500,000$ & 21 & Kab Kuningan & $45,952,500,000$ \\
\hline 8 & Kab Sukabumi & $2,039,633,750,000$ & 22 & Kab Tasikmalaya & $15,000,000,000$ \\
\hline 9 & Kota Bekasi & $1,254,515,000,000$ & 23 & Kota Sukabumi & $13,125,000,000$ \\
\hline 10 & Kab Majalengka & $1,052,292,500,000$ & 24 & Kab Ciamis & 0 \\
\hline 11 & Kab Cianjur & $943,971,250,000$ & 25 & Kab. Pangandaran & 0 \\
\hline 12 & Kota Depok & $814,545,000,000$ & 26 & Kota Banjar & 0 \\
\hline 13 & Kota Bogor & $764,465,000,000$ & 27 & Kota Tasikmalaya & \\
\hline 14 & Kab Indramayu & $626,518,750,000$ & & Total & $135,324,226,250,000$ \\
\hline
\end{tabular}

Sumber : Bidang Pengendalian BPMPT Provinsi Jawa Barat, Data Diolah

Lokasi yang paling besar jumlah minat investasi PMA Januari - Desember 2015 di Jawa Barat, terpusat di Kabupaten Subang dengan nilai investasi sebesar Rp.64,891,962,500,000 dengan rasio investasi sebesar $47.95 \%$, peringkat kedua minat investasi PMA adalah Kabupaten Karawang dengan nilai investasi Rp.24,331,316,250,000 dengan rasio investasi sebesar $17.98 \%$, peringkat ketiga minat investasi PMA adalah
Kabupaten Bekasi dengan nilai investasi Rp.23,749,508,750,000 dan rasio investasi sebesar $17.55 \%$, peringkat keempat adalah Kabupaten Bogor Rp.4,255,572,500,000 dengan nilai rasio investasi $3.14 \%$ sedangkan peringkat kelima adalah Kabupaten Bandung Barat dengan nilai investasi PMA sebesar Rp.2,972,327,500,000 dengan nilai investasi $2.20 \%$. Investasi minat PMA kota dan Kabupaten pada gambar berikut. 


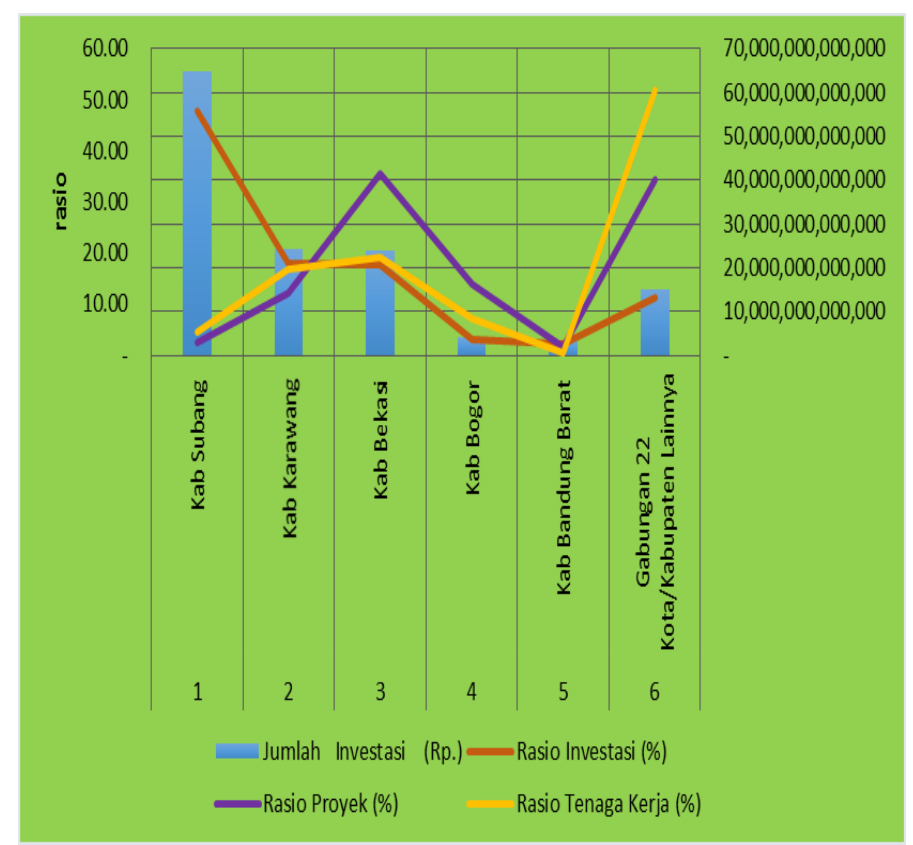

Sumber : Bidang Pengendalian BPMPT Provinsi Jawa Barat, Data Diolah

\section{Gambar 4. Lima Besar Minat Investasi PMA Januari - Desember 2015 di Jawa Barat Berdasarkan Lokasi}

Minat investasi PMA berdasarkan sektor usaha paling diminati investor adalah Januari - Desember 2015 di Jawa Barat yaitu pada bidang usaha listrik, gas dan air sebesar Rp.64,262,130,000,000 dengan rasio investasi sebesar $47.49 \%$. dimana jumlah minat investasi PMA berdasarkan usaha Januari Desember $2015 \quad$ sebesar Rp.135,324,226,250,000 dengan rencana penyerapan tenaga kerja sebesar 83.479 dan rencana proyek sebanyak 611 proyek PMA.
Minat investasi PMA pada peringkat pertama yaitu pada sektor usaha listrik, gas dan air seperti yang diuraikan diatas, sedangkan minat investasi PMA kedua adalah sektor usaha industri kendaraan bermotor \& alat transportasi lain sebesar Rp.21,946,236,250,000 dengan rasio 16.22\%, dan 3 sektor usaha lainnya seperti pada gambar berikut. 


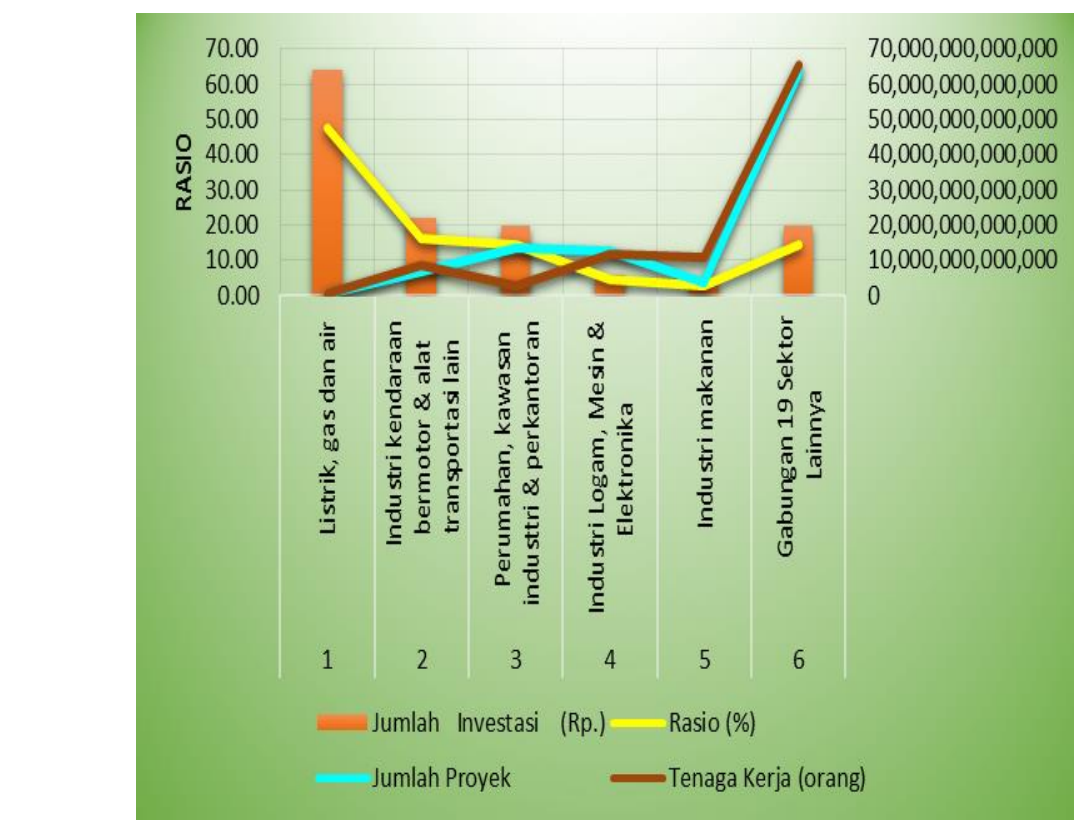

Sumber : Bidang Pengendalian BPMPT Provinsi Jawa Barat, Data Diolah

\section{Gambar 5. Lima Besar Minat Investasi PMA Januari - Desember 2015 di Jawa Barat Berdasarkan Sektor Usaha}

Minat Investasi PMDN Januari - dengan nilai investasi terbesar yaitu Desember 2015 Berdasarkan Lokasi dan Kabupaten Karawang sebesar Sektor Usaha

Minat investasi untuk PMDN di Jawa Barat Januari - Desember 2015, dengan rencana total investasi PMDN sebesar Rp.51,167,514,900,000 untuk tenaga kerja pada Januari - Desember 2015 sebesar 78.082 orang dengan 929 proyek.

Lima besar minat investasi PMDN Rp.14,645,082,000,000 dengan rasio investasi sebesar $28.62 \%$. Peringkat kedua minat investsai PMDN adalah Kabupaten Bogor sebesar Rp.10,523,896,400,000 dan ketiga adalah Kota Bekasi dengan nilai investasi Rp.7,542,588,700,000, sedangkan Kota dan Kabupaten lainnya bisa dilihat pada gambar dibawah ini. berdasarkan lokasi Januari - Desember 2015,

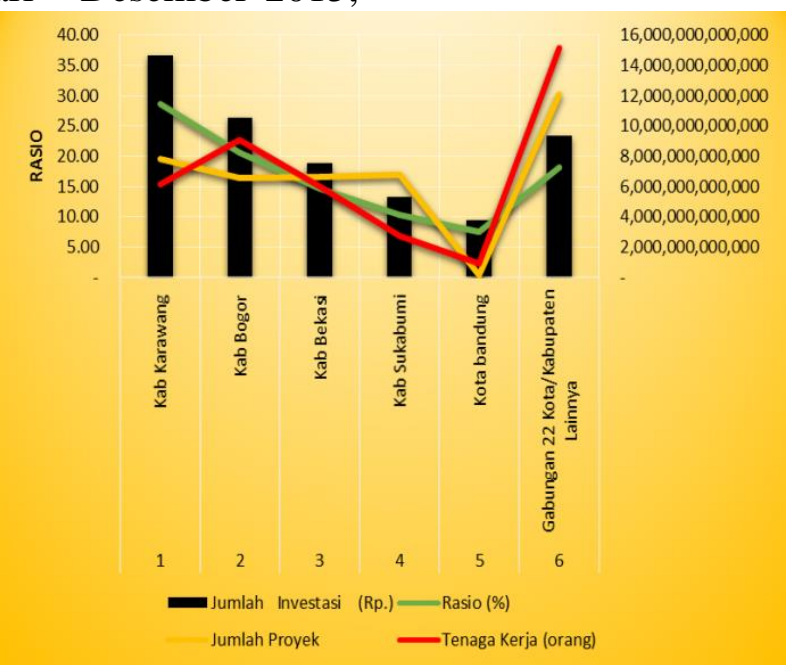

Sumber : Bidang Pengendalian BPMPT Provinsi Jawa Barat, Data Diolah

\section{Gambar 6. Lima Besar Minat Investasi PMDN Januari - Desember 2015 di Jawa Barat Berdasarkan Lokasi}


Rancana minat investasi PMDN Januari - Desember $2015 \quad$ mencapai Rp.51,167,514,900,000 dengan total proyek sebanyak 929 proyek dan total tenaga kerja sebanyak 78.082 orang. Dapat dilihat dengan detail pada tabel 2 dibawah ini.

Tabel 2. Total Investasi PMDN Jawa Barat Januari - Desember 2015, Berdasarkan Sektor Usaha.

\begin{tabular}{|c|c|c|c|c|c|}
\hline 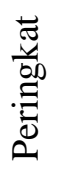 & SEKTOR USAHA & $\begin{array}{c}\text { Jumlah Investasi } \\
\text { (Rp.) }\end{array}$ & $\begin{array}{l}\frac{\vec{\pi}}{000} \\
\cdot 0 \\
0 \\
0 \\
0\end{array}$ & SEKTOR USAHA & $\begin{array}{l}\text { Jumlah Investasi } \\
\text { (Rp.) }\end{array}$ \\
\hline 1 & $\begin{array}{l}\text { Industri kimia \& } \\
\text { farmasi }\end{array}$ & $9,141,243,200,000$ & 13 & $\begin{array}{l}\text { Industri mineral } \\
\text { non logam }\end{array}$ & $1,809,709,200,000$ \\
\hline 2 & $\begin{array}{l}\text { Perumahan, kawasan } \\
\text { industri \& perkantoran }\end{array}$ & $6,149,096,100,000$ & 14 & Pertambangan & $1,690,927,300,000$ \\
\hline 3 & Konstruksi & $5,468,439,100,000$ & 15 & $\begin{array}{l}\text { Industri Karet \& } \\
\text { Plastik }\end{array}$ & $895,775,000,000$ \\
\hline 4 & Jasa Lainnya & $3,955,105,900,000$ & 16 & Industri lainnya & $678,545,500,000$ \\
\hline 5 & Listrik, gas dan air & $3,570,509,900,000$ & 17 & $\begin{array}{l}\text { Perdagangan \& } \\
\text { reparasi }\end{array}$ & $669,621,200,000$ \\
\hline 6 & Industri makanan & $3,240,557,400,000$ & 18 & $\begin{array}{l}\text { Industri barang dari } \\
\text { kulit \& alas kaki }\end{array}$ & $127,254,900,000$ \\
\hline 7 & $\begin{array}{l}\text { Industri kendaraan } \\
\text { bermotor \& alat } \\
\text { transportasi lain }\end{array}$ & $3,223,406,700,000$ & 19 & Peternakan & $80,473,400,000$ \\
\hline 8 & $\begin{array}{l}\text { Industri kertas \& } \\
\text { percetakan }\end{array}$ & $2,638,093,000,000$ & 13 & $\begin{array}{l}\text { Industri mineral } \\
\text { non logam }\end{array}$ & $1,809,709,200,000$ \\
\hline 9 & $\begin{array}{l}\text { Industri Logam, Mesin } \\
\text { \& Elektronika }\end{array}$ & $2,058,397,100,000$ & 14 & Pertambangan & $1,690,927,300,000$ \\
\hline 10 & Hotel \& restoran & $2,013,484,000,000$ & 15 & $\begin{array}{l}\text { Industri Karet \& } \\
\text { Plastik }\end{array}$ & $895,775,000,000$ \\
\hline 11 & Industri tekstil & $1,840,935,000,000$ & 16 & Industri lainnya & $678,545,500,000$ \\
\hline 12 & $\begin{array}{l}\text { Transportasi, gudang \& } \\
\text { komunikasi }\end{array}$ & $1,819,089,200,000$ & 17 & $\begin{array}{l}\text { Perdagangan \& } \\
\text { reparasi }\end{array}$ & $669,621,200,000$ \\
\hline \multicolumn{5}{|c|}{ Total } & $51,167,514,900,000$ \\
\hline
\end{tabular}

Sumber : Bidang Pengendalian BPMPT Provinsi Jawa Barat, Data Diolah

Lima besar minat investasi PMDN Januari Desember 2015 berdasarkan sektor usaha adalah 1) sektor usaha industri kimia \& farmasi dengan nilai investasi sebesar Rp.9,141,243,200,000, 2) sektor usaha perumahan, kawasan industri \& perkantoran dengan nilai investasi sebesar
Rp.6,149,096,100,000, 3) sektor usaha konstruksi dengan nilai investasi sebesar Rp.5,468,439,100,000, 4) sektor usaha jasa lainnya dengan nilai investasi sebesar Rp.3,955,105,900,000, 5) sektor usaha listrik, gas dan air dengan nilai investasi sebesar Rp.3,570,509,900,000. 


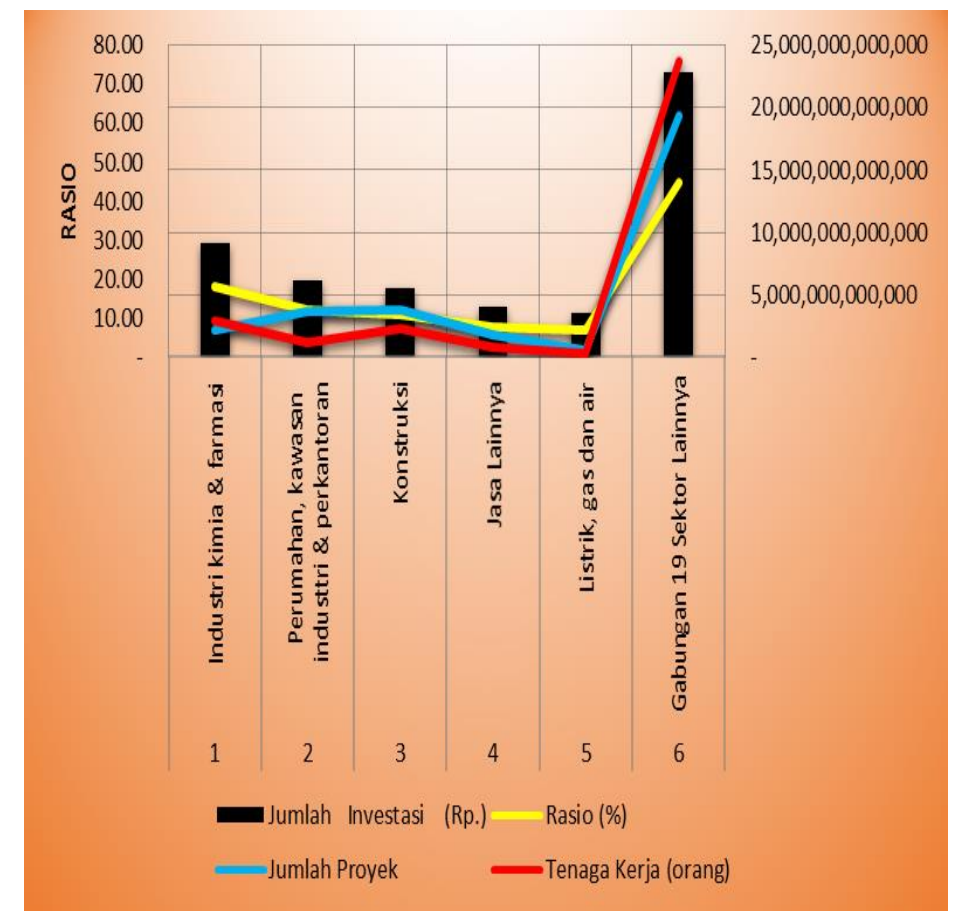

Sumber : Bidang Pengendalian BPMPT Provinsi Jawa Barat, Data Diolah

\section{Gambar 7. Lima Besar Minat Investasi PMDN Januari - Desember 2015 di Jawa Barat Berdasarkan Sektor Usaha}

Realisasi Investasi PMA dan PMDN Januari - Desember 2015 Berdasarkan Lokasi dan Sektor Usaha

Investasi PMA dan PMDN di Jawa Barat pada Januari - Desember 2015 telah direalisasikan oleh para investor di 27 (dua puluh tujuh) Kabupaten/Kota mencapai nilai total sebesar Rp.121,516,952,815,583 dengan jumlah penyerapan tenaga kerja sebanyak 349.377, serta jumlah proyek sebanyak 37.213 proyek.

Tabel 3. Total Realisasi Investasi PMA dan PMDN Jawa Barat Januari - Desember 2015, Berdasarkan Lokasi.

\begin{tabular}{|c|c|c|c|c|c|}
\hline 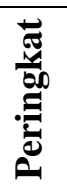 & KAB./KOTA & $\begin{array}{c}\text { Jumlah Investasi } \\
\text { (Rp.) }\end{array}$ & 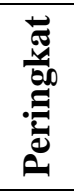 & KAB./KOTA & $\begin{array}{c}\text { Jumlah Investasi } \\
\text { (Rp.) }\end{array}$ \\
\hline 1 & Kab Bekasi & $35,126,038,409,629$ & 14 & Kab Bandung & $1,289,774,816,297$ \\
\hline 2 & Kab Karawang & $25,453,640,769,707$ & 15 & Kab Indramayu & $1,109,653,178,054$ \\
\hline 3 & Kota bandung & $12,808,241,277,103$ & 16 & Kab Cianjur & $825,413,495,000$ \\
\hline 4 & Kab Bogor & $9,782,249,764,488$ & 17 & Kab Bandung Barat & $813,206,727,796$ \\
\hline 5 & Kota Bekasi & $6,703,612,465,838$ & 18 & Kota Sukabumi & $705,477,056,600$ \\
\hline 6 & Kab Purwakarta & $5,470,279,392,917$ & 19 & Kab Majalengka & $570,585,856,088$ \\
\hline 7 & Kab Sukabumi & $5,023,402,629,999$ & 20 & Kab Garut & $424,760,900,000$ \\
\hline 8 & Kab Subang & $3,398,423,498,357$ & 21 & Kota Cimahi & $381,336,017,000$ \\
\hline 9 & Kota Bogor & $3,104,313,574,444$ & 22 & Kota Tasikmalaya & $196,256,382,080$ \\
\hline 10 & Kota Depok & $2,552,310,483,648$ & 23 & Kab Tasikmalaya & $180,778,500,000$ \\
\hline
\end{tabular}




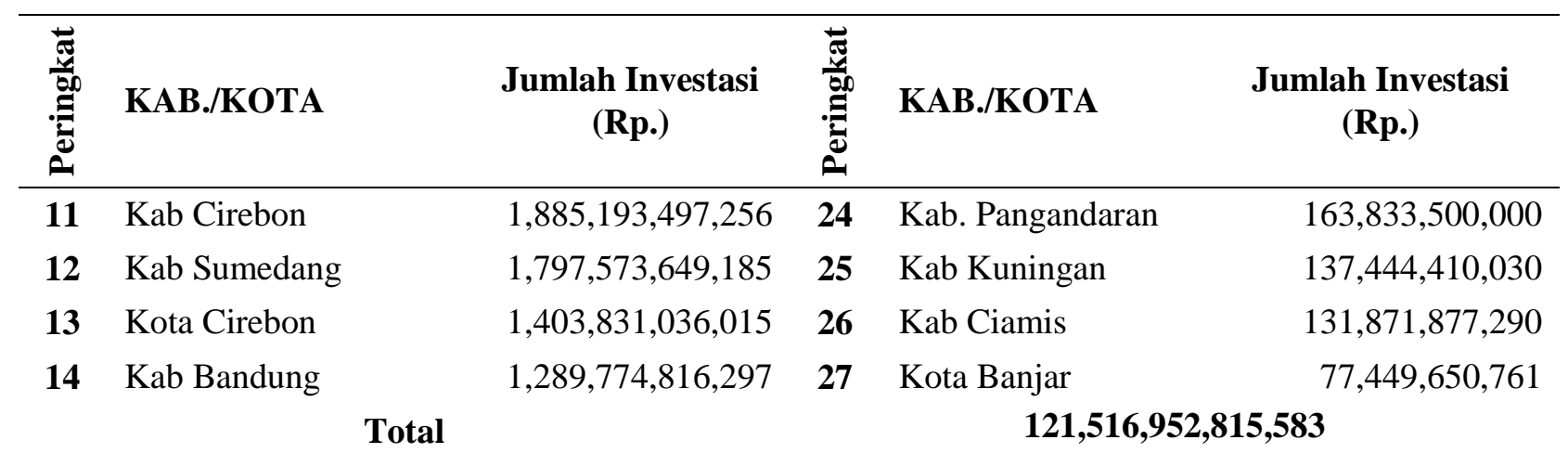

Sumber : Bidang Pengendalian BPMPT Provinsi Jawa Barat, Data Diolah

Pada Januari - Desember 2015 Kabupaten Bekasi merupakan daerah yang menyerap tenaga kerja paling banyak sebesar 121.849 orang dengan 5.828 Proyek.

Realisasi investasi PMA dan PMDN Januari Desember 2015 berdasarkan sektor usaha berjumlah Rp.121,516,952,815,583, dengan nilai proyek sebanyak 37.213 proyek dan mampu menyerap tenaga kerja sebanyak 349.377 orang.

Tabel 4. Total Realisasi Investasi PMA dan PMDN Jawa Barat Januari - Desember 2015, Berdasarkan Sektor Usaha.

\begin{tabular}{|c|c|c|c|c|c|}
\hline م & SEKTOR USAHA & Jumlah Investasi (Rp.) & 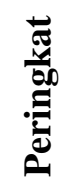 & $\begin{array}{l}\text { SEKTOR } \\
\text { USAHA }\end{array}$ & $\begin{array}{c}\text { Jumlah Investasi } \\
\text { (Rp.) }\end{array}$ \\
\hline 1 & $\begin{array}{l}\text { Perdagangan \& } \\
\text { reparasi }\end{array}$ & $23,991,493,342,854$ & 13 & Listrik, gas dan air & $2,703,293,650,000$ \\
\hline 2 & $\begin{array}{l}\text { Industri kendaraan } \\
\text { bermotor \& alat } \\
\text { transportasi lain }\end{array}$ & $18,563,397,464,938$ & 14 & $\begin{array}{l}\text { Industri kertas \& } \\
\text { percetakan }\end{array}$ & $1,430,321,155,818$ \\
\hline 3 & $\begin{array}{l}\text { Industri Logam, } \\
\text { Mesin \& Elektronika }\end{array}$ & $12,799,416,167,724$ & 15 & Jasa Lainnya & $1,371,717,131,790$ \\
\hline 4 & $\begin{array}{l}\text { Industri kimia \& } \\
\text { farmasi }\end{array}$ & $9,346,645,624,898$ & 16 & $\begin{array}{l}\text { Industri barang } \\
\text { dari kulit \& alas } \\
\text { kaki }\end{array}$ & $1,322,971,251,888$ \\
\hline 5 & Konstruksi & $7,999,765,918,474$ & 17 & Industri lainnya & $668,278,300,000$ \\
\hline 6 & $\begin{array}{l}\text { Industri mineral non } \\
\text { logam }\end{array}$ & $7,913,884,574,258$ & 18 & Peternakan & $621,700,000,000$ \\
\hline 7 & $\begin{array}{l}\text { Transportasi, gudang } \\
\text { \& komunikasi }\end{array}$ & 7,899,197,918,306 & 19 & Pertambangan & $205,652,500,000$ \\
\hline 8 & $\begin{array}{l}\text { Industri Karet \& } \\
\text { Plastik }\end{array}$ & $6,945,530,432,095$ & 20 & Industri kayu & $32,053,898,804$ \\
\hline 9 & Industri makanan & $6,294,318,859,394$ & 21 & $\begin{array}{l}\text { Tanaman Pangan } \\
\& \text { Perkebunan }\end{array}$ & $18,241,750,000$ \\
\hline 10 & $\begin{array}{l}\text { Perumahan, kawasan } \\
\text { industri \& } \\
\text { perkantoran }\end{array}$ & $5,846,318,714,400$ & 22 & Perikanan & $5,837,500,000$ \\
\hline 11 & Industri tekstil & $2,821,738,688,081$ & 23 & $\begin{array}{l}\text { Industri instrumen } \\
\text { kedokteran, } \\
\text { presisi, optik dan } \\
\text { jam }\end{array}$ & $38,750,000$ \\
\hline
\end{tabular}




\begin{tabular}{|c|c|c|c|c|c|}
\hline 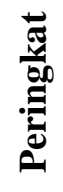 & SEKTOR USAHA & Jumlah Investasi (Rp.) & 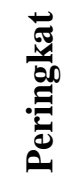 & $\begin{array}{c}\text { SEKTOR } \\
\text { USAHA }\end{array}$ & $\begin{array}{c}\text { Jumlah Investasi } \\
\text { (Rp.) }\end{array}$ \\
\hline 12 & Hotel \& restoran & $2,715,139,221,861$ & 24 & Kehutanan & 0 \\
\hline \multicolumn{3}{|c|}{ Total } & \multicolumn{3}{|c|}{$121,516,952,815,583$} \\
\hline
\end{tabular}

Sumber : Bidang Pengendalian BPMPT Provinsi Jawa Barat, Data Diolah

Realisasi investasi PMA dan PMDN Januari Desember 2015 terbesar pada sektor usaha perdagangan \& reparasi sebanyak Rp.23,991,493,342,854 dengan rasio investasi sebesar $19.74 \%, 82.65 \%$ rasio proyek dan tenaga kerja sebesar $20.62 \%$.
Realisasi Investasi PMA Januari Desember 2015 Berdasarkan Lokasi dan Sektor Usaha

Total realisasi investasi untuk PMA di Jawa Barat Januari - Desember 2015, men c a pai Rp.71,733,928,750,000, mampu menyerap 240.048 orang dengan 5.108 proyek, berdasarkan lokasi dapat dilihat pada taabel 5 dibawah ini.

Tabel 5. Total Realisasi Investasi PMA Jawa Barat Januari - Desember 2015, Berdasarkan Lokasi.

\begin{tabular}{|c|c|c|c|c|c|}
\hline 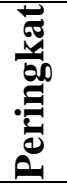 & КАВ./KOTA & $\begin{array}{c}\text { Jumlah Investasi } \\
\text { (Rp.) }\end{array}$ & 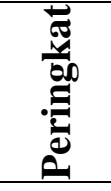 & KAB./KOTA & $\begin{array}{c}\text { Jumlah } \\
\text { Investasi (Rp.) }\end{array}$ \\
\hline 1 & Kab Bekasi & $28,039,438,750,000$ & 15 & Kota Bogor & $264,878,750,000$ \\
\hline 2 & Kab Karawang & $17,813,837,500,000$ & 16 & $\begin{array}{l}\text { Kab Bandung } \\
\text { Barat }\end{array}$ & $206,681,250,000$ \\
\hline 3 & Kota bandung & $6,914,310,000,000$ & 17 & Kab Garut & $200,785,000,000$ \\
\hline 4 & Kab Purwakarta & $4,939,275,000,000$ & 18 & Kab Cirebon & $190,050,000,000$ \\
\hline 5 & Kab Sukabumi & $4,392,851,250,000$ & 19 & Kota Cirebon & $154,208,750,000$ \\
\hline 6 & Kab Subang & $2,418,376,250,000$ & 20 & $\begin{array}{l}\text { Kota } \\
\text { Sukabumi }\end{array}$ & $75,607,500,000$ \\
\hline 7 & Kab Bogor & $2,056,908,750,000$ & 21 & Kota Cimahi & $30,322,500,000$ \\
\hline 8 & Kab Indramayu & $827,563,750,000$ & 22 & $\begin{array}{l}\text { Kota } \\
\text { Tasikmalaya }\end{array}$ & $10,056,250,000$ \\
\hline 9 & Kota Bekasi & $821,216,250,000$ & 23 & $\begin{array}{l}\text { Kab } \\
\text { Tasikmalaya }\end{array}$ & $6,947,500,000$ \\
\hline 10 & Kab Cianjur & $629,271,250,000$ & 24 & $\begin{array}{l}\text { Kab } \\
\text { Kuningan }\end{array}$ & $5,641,250,000$ \\
\hline 11 & Kota Depok & $550,528,750,000$ & 25 & Kab Ciamis & 0 \\
\hline 12 & Kab Bandung & $477,685,000,000$ & 26 & $\begin{array}{l}\text { Kab. } \\
\text { Pangandaran }\end{array}$ & 0 \\
\hline 13 & Kab Sumedang & $354,166,250,000$ & 27 & Kota Banjar & 0 \\
\hline 14 & Kab Majalengka & $353,321,250,000$ & Total & & 1,733,928,750,000 \\
\hline
\end{tabular}

Sumber : Bidang Pengendalian BPMPT Provinsi Jawa Barat, Data Diolah 
Kota/Kabupaten di Jawa Barat yang paling besar atas realisasi investasi PMA Januari Desember 2015, terpusat di Kota Bekasi sebesar Rp.28,039,438,750,000 atau sebesar
39.09\% dari total investasi PMA di Jawa Barat, sedangkan peringkat kedua pada Kabupaten Karawang dengan nilai Rp.17,813,837,500,000.

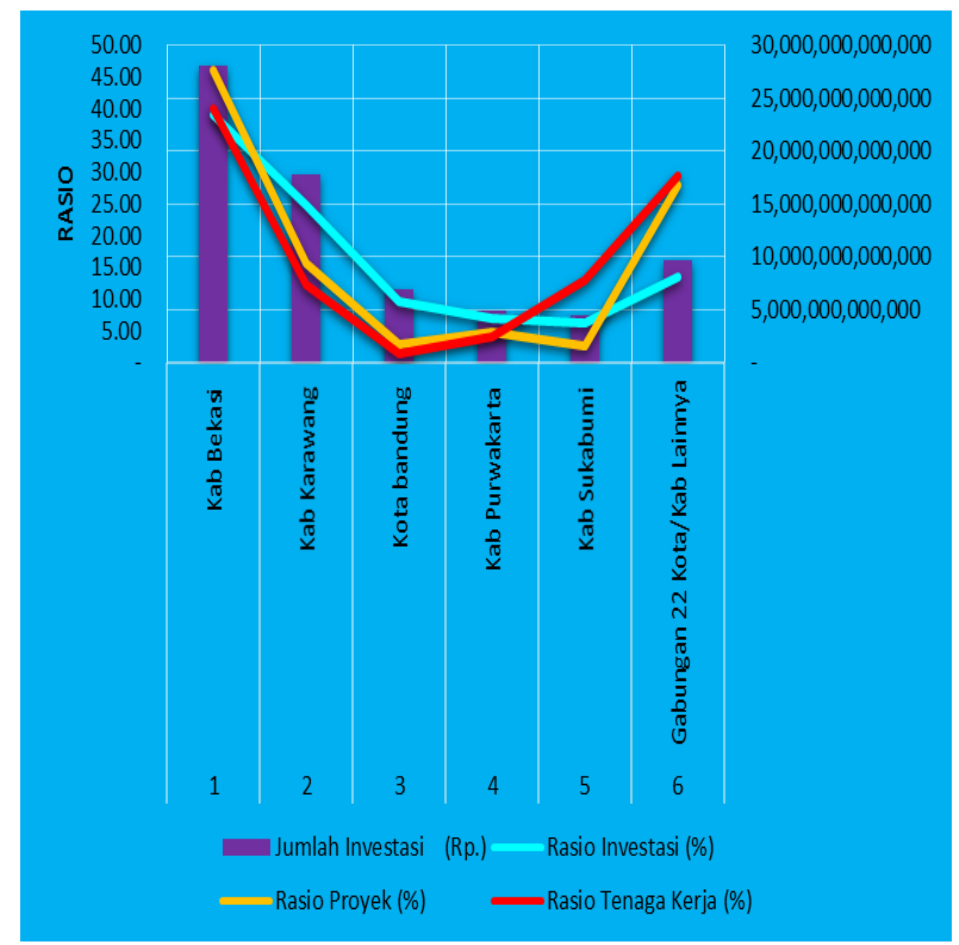

Sumber : Bidang Pengendalian BPMPT Provinsi Jawa Barat, Data Diolah

\section{Gambar 7. Rasio Lima Besar Realisasi Investasi PMA Januari - Desember 2015 di Jawa Barat Berdasarkan Lokasi}

Realisasi investasi PMA Januari - Desember 2015 berdasarkan sektor usaha dengan nilai sebesar Rp. 71,733,928,750,000, dengan total proyek sebanyak 5.108 proyek mampu menyerap tenaga kerja sebanyak 240.048 orang.

Tabel 6. Total Realisasi Investasi PMA Jawa Barat Januari - Desember 2015, Berdasarkan Sektor Usaha.

\begin{tabular}{|c|c|c|c|c|c|}
\hline 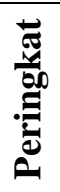 & SEKTOR USAHA & $\begin{array}{c}\text { Jumlah Investasi } \\
\text { (Rp.) }\end{array}$ & 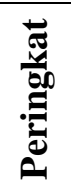 & $\begin{array}{l}\text { SEKTOR } \\
\text { USAHA }\end{array}$ & $\begin{array}{c}\text { Jumlah Investasi } \\
\text { (Rp.) }\end{array}$ \\
\hline 1 & $\begin{array}{l}\text { Industri kendaraan } \\
\text { bermotor \& alat } \\
\text { transportasi lain }\end{array}$ & $17,947,980,000,000$ & 13 & $\begin{array}{l}\text { Industri barang } \\
\text { dari kulit \& } \\
\text { alas kaki }\end{array}$ & $1,321,521,250,000$ \\
\hline 2 & $\begin{array}{l}\text { Industri Logam, Mesin } \\
\text { \& Elektronika }\end{array}$ & $11,013,648,750,000$ & 14 & Peternakan & $620,000,000,000$ \\
\hline 3 & $\begin{array}{l}\text { Transportasi, gudang \& } \\
\text { komunikasi }\end{array}$ & $7,427,571,250,000$ & 15 & Jasa Lainnya & $613,452,500,000$ \\
\hline 4 & Industri Karet \& Plastik & $5,711,047,500,000$ & 16 & $\begin{array}{l}\text { Industri kertas } \\
\& \text { percetakan }\end{array}$ & $471,403,750,000$ \\
\hline 5 & Perumahan, kawasan & $5,207,633,750,000$ & 17 & Industri & $358,040,000,000$ \\
\hline
\end{tabular}




\begin{tabular}{|c|c|c|c|c|c|}
\hline & industri \& perkantoran & \multicolumn{4}{|c|}{ lainnya } \\
\hline 6 & Industri kimia \& farmasi & $4,117,693,750,000$ & 18 & Pertambangan & $198,683,750,000$ \\
\hline 7 & Konstruksi & $3,765,988,750,000$ & 19 & $\begin{array}{l}\text { Listrik, gas dan } \\
\text { air }\end{array}$ & $156,690,000,000$ \\
\hline 8 & $\begin{array}{l}\text { Industri mineral non } \\
\text { logam }\end{array}$ & $3,375,312,500,000$ & 20 & Industri kayu & $11,875,000,000$ \\
\hline 9 & Perdagangan \& reparasi & $3,182,668,750,000$ & 21 & $\begin{array}{l}\text { Perikanan } \\
\text { Tanaman }\end{array}$ & $5,837,500,000$ \\
\hline 10 & Industri makanan & $2,644,068,750,000$ & 22 & $\begin{array}{l}\text { Pangan \& } \\
\text { Perkebunan } \\
\text { Industri } \\
\text { instrumen }\end{array}$ & $4,837,500,000$ \\
\hline 11 & Industri tekstil & $2,136,307,500,000$ & 23 & $\begin{array}{l}\text { kedokteran, } \\
\text { presisi, optik } \\
\text { dan jam }\end{array}$ & $38,750,000$ \\
\hline 12 & Hotel \& restoran & $1,441,627,500,000$ & 24 & $\begin{array}{l}\text { Kehutanan } \\
\mathbf{7 1 , 7 3 3 , 9 2 8}\end{array}$ & 000 \\
\hline
\end{tabular}

Sumber : Bidang Pengendalian BPMPT Provinsi Jawa Barat, Data Diolah

Sektor yang paling besar jumlah realisasi investasi PMA Januari - Desember 2015 di Jawa Barat bidang usaha industri kendaraan bermotor dan alat transportasi lain sebesar Rp.17,947,980,000,000 atau $25.02 \%$ dari total realisasi investasi PMA di Jawa Barat.

\section{Realisasi Investasi PMDN Jawa Barat Januari - Desember 2015 Berdasarkan Data SPIPISE dan Non SPIPISE}

Realisasi total investasi PMDN berdasarkan data SPIPISE dan Non SPIPISE Januari Desember 2015 berdasarkan lokasi mencapai Rp.49,783,024,065,583, dengan jumlah LKPM sebanyak 32.105 dengan jumlah tenaga kerja sebanyak 109.329 orang. Realisasi PMDN data SPIPISE berdasarkan lokasi Januari - Desember 2015 mencapai Rp.26,272,865,550,000 dan realisasi PMDN Non SPIPISE berdasarkan lokasi mencapai Rp.23,510,158,515,583.

Tabel 7. Total Realisasi Investasi PMDN Jawa Barat Januari - Desember 2015, Berdasarkan Lokasi (SPIPISE dan Non SPIPISE).

\begin{tabular}{|c|c|c|c|c|c|}
\hline 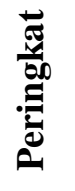 & KAB./KOTA & Jumlah Laporan & 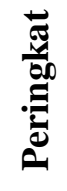 & КАВ./КОТА & Jumlah Laporan \\
\hline 1 & Kab Bogor & $7,725,341,014,488$ & 15 & $\begin{array}{l}\text { Kab Bandung } \\
\text { Barat }\end{array}$ & $606,525,477,796$ \\
\hline 2 & Kab Karawang & $7,639,803,269,707$ & 16 & $\begin{array}{l}\text { Kab } \\
\text { Purwakarta }\end{array}$ & $531,004,392,917$ \\
\hline 3 & Kab Bekasi & $7,086,599,659,629$ & 17 & Kota Cimahi & $351,013,517,000$ \\
\hline 4 & Kota bandung & $5,893,931,277,103$ & 18 & $\begin{array}{l}\text { Kab } \\
\text { Indramayu }\end{array}$ & $282,089,428,054$ \\
\hline 5 & Kota Bekasi & $5,882,396,215,838$ & 19 & Kab Garut & $223,975,900,000$ \\
\hline 6 & Kota Bogor & $2,839,434,824,444$ & 20 & $\begin{array}{l}\text { Kab } \\
\text { Majalengka }\end{array}$ & $217,264,606,088$ \\
\hline 7 & Kota Depok & $2,001,781,733,648$ & 21 & Kab Cianjur & $196,142,245,000$ \\
\hline 8 & Kab Cirebon & $1,695,143,497,256$ & 22 & Kota & $186,200,132,080$ \\
\hline
\end{tabular}




\begin{tabular}{|c|c|c|c|c|c|}
\hline 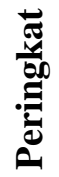 & КАВ./КОТА & Jumlah Laporan & 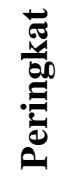 & KAB./KOTA & Jumlah Laporan \\
\hline & & & & Tasikmalaya & \\
\hline 9 & Kab Sumedang & $1,443,407,399,185$ & 23 & $\begin{array}{l}\text { Kab } \\
\text { Tasikmalaya }\end{array}$ & $173,831,000,000$ \\
\hline 10 & Kota Cirebon & $1,249,622,286,015$ & 24 & $\begin{array}{l}\text { Kab. } \\
\text { Pangandaran }\end{array}$ & $163,833,500,000$ \\
\hline 11 & Kab Subang & $980,047,248,357$ & 25 & Kab Ciamis & $131,871,877,290$ \\
\hline 12 & Kab Bandung & $812,089,816,297$ & 26 & Kab Kuningan & $131,803,160,030$ \\
\hline 13 & Kab Sukabumi & $630,551,379,999$ & 27 & Kota Banjar & $77,449,650,761$ \\
\hline 14 & Kota Sukabumi & $629,869,556,600$ & & \multicolumn{2}{|c|}{ Total 49,783,024,065,583 } \\
\hline
\end{tabular}

Sumber : Bidang Pengendalian BPMPT Provinsi Jawa Barat, Data Diolah

Lokasi yang paling besar jumlah investasi PMDN (SPIPISE dan Non SPIPISE) Januari Desember 2015 berdasarkan lokasi di Jawa Barat, diinvestasikan di Kabupaten Bogor sebesar Rp.7,725,341,014,488 atau 15,52 \% dari total investasi realisasi PMDN (SPIPISE dan Non SPIPISE) di Jawa Barat.

\section{SIMPULAN}

Bedasarkan hasil penelitian yang dilakukan untuk melihat perkembangan Minat dan Realisasi Investasi Penanaman Modal Asing (PMA) dan Penanaman Modal Dalam Negeri (PMDN) yang telah diuraikan sebelumnya, maka dapat disimpulkan (1) Pertumbuhan Minat Penanaman Modal Asing (PMA) berdasarkan Lokasi Kabupaten/Kota dan Sektor Usaha Provinsi Jawa Barat mencapai sebesar Rp.135,324,226,250,000 dengan rencana tenaga kerja sebesar 83.479 orang, sedangkan rencana proyek PMA sebanyak 611. Peringkat pertama investasi yang menarik minat investor adalah Kabupaten Subang dengan nilai investasi Rp.64,891,962,500,000, sedangkan peringkat pertama investasi berdasarkan Sektor Usaha adalah sektor usaha listrik, gas dan air sebesar Rp.64,262,130,000,000. (2) Realisasi Penanaman Modal Asing (PMA) berdasarkan Lokasi Kabupaten/Kota dan Sektor Usaha Provinsi Jawa Barat mencapai Rp.71,733,928,750,000, mampu menyerap
240.048 orang dengan 5.108 proyek. Peringkat pertama realisasi investasi adalah Kabupaten Bekasi dengan nilai investasi Rp.28,039,438,750,000, sedangkan peringkat pertama realisasi investasi berdasarkan Sektor Usaha adalah sektor usaha industri kendaraan bermotor dan alat transportasi lain sebesar Rp.17,947,980,000,000. (3) Pertumbuhan Minat Penanaman Modal Dalam Negeri (PMDN) Kabupaten/Kota dan Sektor Usaha Provinsi Jawa Barat mencapai sebesar Rp.51,167,514,900,000 untuk tenaga kerja pada Januari - Desember 2015 sebesar 78.082 orang dengan 929 proyek. Peringkat pertama investasi PMDN yang menarik minat investor adalah Kabupaten Karawang dengan nilai investasi Rp.14,645,082,000,000, sedangkan peringkat pertama investasi PMDN berdasarkan Sektor Usaha adalah sektor usaha industri kimia \& farmasi dengan nilai investasi sebesar Rp.9,141,243,200,000. (4) Realisasi Penanaman Modal Dalam Negeri (PMDN) berdasarkan Lokasi Kabupaten/Kota dan Sektor Usaha Provinsi Jawa Barat mencapai mencapai Rp.49,783,024,065,583, dengan jumlah LKPM sebanyak 32.105 dengan jumlah tenaga kerja sebanyak 109.329 orang. Realisasi PMDN data SPIPISE berdasarkan lokasi Januari - Desember 2015 mencapai Rp.26,272,865,550,000 dan realisasi PMDN Non SPIPISE berdasarkan lokasi mencapai Rp.23,510,158,515,583. Peringkat pertama realisasi investasi adalah Kabupaten Bogor sebesar 
Rp.7,725,341,014,488, sedangkan peringkat pertama realisasi investasi berdasarkan Sektor Usaha adalah usaha perdagangan dan reparasi pada peringkat pertama sebesar Rp.20,808,824,592,854.

Mengacu pada simpulan hasil penelitian bahwaperkembangan Minat dan Realisasi Investasi Penanaman Modal Asing (PMA) dan Penanaman Modal Dalam Negeri (PMDN), yang telah diuraikan sebelumnya, maka terdapat beberapa saran yang dapat diberikan (1) Memberi perlakuan yang sama bagi penanam modal dalam negeri dan penanam modal asing dengan tetap memperhatikan dan mengedepankan kepentingan nasional. (2) Menjamin kepastian hukum, kepastian berusaha, dan keamanan berusaha bagi penanam modal sejak proses pengurusan perizinan sampai dengan berakhirnya kegiatan penanaman modal sesuai dengan ketentuan peraturan perundangundangan. (3) Membuka kesempatan bagi perkembangan dan memberikan perlindungan kepada usaha mikro, kecil, menengah, dan koperasi.

\section{DAFTAR PUSTAKA}

Badan Koordinasi Penanaman Modal Rapublik Indonesia. 2015. Realisasi Penanaman Modal PMA - PMD Triwulan IV dan Januari - Desember 2014.

Badan Pusat Statistik Provinsi Jawa Barat. 2015. Produk Domestik Regional Bruto (PDRB) Menurut Pengeluaran Provinsi Jawa Barat 2010-2014, ISSN : 0854.9303

Depatement Statistik Ekonomi dan Moneter, Bank Indoensia.___. Produk Domestik Regional Bruto (PDRB). http://www.bi.go.id/id/statistik/metada ta/sekda/Documents/8PDRBSEKDA1. pdf. [24 Juni 2015]

Gitman, Lawrence J and Chad J. Zutter. 2012. Priciples Of Managerial Finance, $13^{\text {th }}$ Edition. United Stated of America : Prentice Hall.
J.R, Raco. 2013. Metode Penelitian Kualitatif Jenis Karakteristik dan Keunggulannya. Grasindo. Jakarta.

Kimbal, R.W. 2015. Modal Sosial dan Ekonomi Industri Kecil Sebuah Studi Kualitatif. Deepublish. Yogyakarta.

Lesty Phytaloka. 2010. Analisis Faktor-Faktor Yang Memengaruhi Penanaman Modal Asing Dan Peluang Investasi. Bogor. Departemen Ilmu Ekonomi, Fakultas Ekonomi Dan Manajemen, Institut Pertanian Bogor.

Tandelilin, Eduardus. 2010. Portofolio dan Investasi (Teori dan Aplikasi). Edisi Pertama. Yogyakarta : Penerbit Kanisius. 